\title{
O uso do Sistema de Posicionamento Global (GPS) como ferramenta para Educaçáo Ambiental
}

\author{
The use of Global Positioning System (GPS) as a tool for Environmental Education
}

\author{
Daniel de Sampaio ${ }^{1}$ \\ Maria de Fátima Alves de Oliveira ${ }^{2}$
}

\section{Resumo}

Este trabalho é resultado de uma pesquisa que tem como objetivo criar uma metodologia para construção de mapas utilizando GPS. Essa metodologia é uma tentativa de diminuir o grande hiato que há entre os conteúdos ensinados em sala e sua real aplicabilidade no cotidiano. Os alunos do $1^{\circ}$ ano do Ensino Médio foram escolhidos para a realização desta proposta, pois o currículo desta referida série abrange o ensino de Cartografia e de questôes ambientais. O objetivo é promover a Alfabetização Cartográfica utilizando a Educação Ambiental para mostrar aos alunos como os conceitos estudados em sala são utilizados no cotidiano. O projeto foi estruturado em três fases: na primeira foram trabalhados os conteúdos normais do programa em sala. $\mathrm{Na}$ segunda fase os alunos foram para a rua com um GPS e máquina fotográfica para marcarem pontos de interesse e fotografarem as ocorrências registradas. $\mathrm{Na}$ terceira fase os dados coletados foram transferidos para os computadores, onde foram confeccionados diversos tipos de mapas com os dados registrados em campo. Os alunos conseguiram assimilar melhor os conceitos, signos e significados com a metodologia utilizada em comparação quando há apenas aulas teóricas. Os comentários positivos de alunos e professores nos levam a pensar que a metodologia utilizada obteve êxito.

Pavavras-chave: Educação Ambiental, Alfabetização Cartográfica, GPS.

\begin{abstract}
This work is a result of research that aims to create a methodology for building maps using GPS. This methodology is an attempt to reduce the wide gap that exists between the content taught in class and its real applicability in daily life. Students in 1st year of secondary school were chosen to implement this proposal because the curriculum of this series covers the teaching of cartography and environmental issues. The goal is to promote literacy using Cartographic Environmental Education to show students how the concepts studied in class are used in everyday life. The project was structured in three phases: the first were worked normal content of the program in the classroom. In the second phase the students were on the road with a GPS and camera to mark points of interest and photographing the events recorded. In the third phase the data collected were transferred to computers, where they made different types of maps with the data recorded in the field. Students were able to better assimilate the concepts, symbols and meanings with the methodology used for comparison when there are only theoretical. The positive comments from students and teachers lead us to think that the methodology was successful.
\end{abstract}

Keywords: Environmental Education, Cartographic Literacy, GPS.

\footnotetext{
${ }^{1}$ Graduado em Geografia, pós-graduado em Geo-História e Preservação do Meio Ambiente, mestrando em Ensino em Ciências da Saúde e do Meio Ambiente do UNIFOA - Centro Universitário de Volta Redonda.

${ }^{2}$ Professora do LAEFIB/IOC/Fiocruz e do Mestrado Profissional em Ensino em Ciências da Saúde e do Meio Ambiente do UNIFOA - Centro Universitário de Volta Redonda.
} 


\section{INTRODUÇÃO}

A nova proposta de avaliação do Ministério da Educação (MEC) através do Exame Nacional do Ensino Médio (ENEM) valoriza o aprendizado dos conteúdos aliados tanto a situaçóes problemas do cotidiano dos estudantes, quanto ao uso de novas tecnologias educacionais. Nas aulas de Geografia, alguns alunos apresentam dificuldades em relacionar os conteúdos aprendidos em sala de aula para resolver situaçóes que ocorrem a sua volta, por ignorar a interpretação e análise de mapas. Eles não conseguem identificar os principais elementos que compóem um mapa, fazer a leitura de escala e abstrair os principais signos e significados que os mapas apresentam. Assim não fazem uma correta interpretação do mapa.

$\mathrm{Na}$ tentativa de diminuir essa dificuldade, utilizamos uma metodologia diferenciada que faz parte do projeto de pesquisa do mestrado desenvolvida no programa com os alunos do $1^{\circ}$ ano do Ensino Médio de uma escola pública, localizado em Barra Mansa, estado do Rio de Janeiro, ao apresentar o tema.

A propósito, Berg (2006) comenta a importância de se mapear a regiáo onde se vive, pois enriquece o ponto de vista pessoal e se consegue perceber todos os elementos naturais e culturais que estão inseridos nesse território. Por isso a opçáo por se trabalhar a construção de mapas de Biorregião é apresentada nesse projeto.

A busca de novas formas de ensino deve fazer parte do cotidiano escolar para atender a sociedade atual, pois com a evolução da técnica e novas formas de relaçôes entre as pessoas, a escola precisa estar pronta para atender a essa nova realidade e buscar novas formas de ensino que integrem o uso de instrumentos tecnológicos no processo de ensino/aprendizagem. Carvalho (2011) nos lembra que: "Compartilhando dessa intencionalidade educativa, o projeto político-pedagógico de uma Educação Ambiental (EA) crítica poderia ser descrito como a formação de um sujeito capaz de "ler" seu ambiente e interpretar as relaçôes, os conflitos e os problemas aí presentes".

A escola do século XXI precisa contribuir para a construção da cidadania. Mas o desafio da escola, principalmente a pública, de construir um cidadão consciente é complexo devido à heterogeneidade sociocultural dos alunos em relação à idade e valores. Teixeira (2009, p. 184) ao abordar o tema comenta:

"Estamos formando hoje os profissionais do futuro e não dá mais para pensar/fazer essa formação sem considerar, no mínimo, 3 aspectos: o mundo e sua comunicação global através da Teleinformática; o mundo e sua sociedade global através da Interdisciplinaridade; e o mundo e sua ciência global através do conhecimento de uma Realidade Complexa”.
Para Pontuschka (2001), a Geografia no ensino fundamental e médio precisa formar uma criança e um jovem que deverão se movimentar bem no mundo de hoje, com a complexa realidade deste final de milênio, e ainda prepará- los para enfrentar outras transformaçôes que estão por vir. A construção de mapas aliados a projetos de educação ambiental ajudam o aluno a perceber melhor o local onde vive, estabelecer novas relaçóes e desenvolver senso crítico.

A Lei 9.795/99 reafirma esse pensamento no parágrafo terceiro do oitavo artigo, onde encontramos: o desenvolvimento de instrumentos e metodologias, visando à incorporação da dimensão ambiental, de forma interdisciplinar, nos diferentes níveis e modalidades de ensino (BRASIL, 1999). A produção de mapas de Biorregião pode contribuir não só com o ensino de geografia, mas com várias disciplinas. Outro aspecto importante é a utilização de recursos tecnológicos no processo de ensino/aprendizagem, hoje essencial para promover uma educação mais próxima da realidade do aluno.

Ainda segundo Pontuschka (op. cit.), "conhecer os alunos, as representaçôes sociais e os saberes que trazem são as primeiras tarefas do professor de qualquer disciplina”. Mapear a Biorregião vai ao encontro desse pensamento, pois, no processo de construção de um mapa de Biorregião se faz necessário conhecer as pessoas que ali vivem e suas representaçôes e saberes, porque são esses valores que moldam o espaço geográfico. Os objetos ali presentes são a expressão material da ação da sociedade sobre o seu espaço socialmente construído. Deixar de lado essa interpretação da relação homem x meio no processo histórico não levará o aluno a refletir sobre o local em que vive e não será possível, então, desenvolver a metodologia proposta do mapeamento da Biorregião.

Reigota (2009) observou que "os problemas ambientais foram criados por homens e mulheres e deles virão às soluçôes". Estas não serão obras de gênios, de políticos ou tecnocratas, mas sim de cidadãos e cidadãs. Por isso trabalhar a educação ambiental na escola é um importante caminho de conscientização ambiental e em consequência, de construção da cidadania.

Rodrigues (2008) numa análise sobre a importância da educação ambiental na formação da cidadania, diz que "a politização da EA pode abrir caminhos para a construção de uma sustentabilidade emancipatória baseada na defesa da vida em largo sentido, da liberdade e da justiça social". Em adição a esse pensamento, mapear a Biorregiâo estimula o aluno a refletir o meio a sua volta e a partir dessa observação pode analisar com maior consciência os problemas que o cercam. A busca por melhorias das condiçóes do local em que se vive é um direito de qualquer cidadão, mas para propor mudanças é preciso conhecer o que está a sua volta. Um caminho a seguir para melhor compreensão da Biorre- 
giáo é o aluno ser um agente participativo do processo de mapeamento da Biorregiáo dentro de um projeto interdisciplinar de educação ambiental. Como descreve Stefanello (2009) "o estudo através das representaçôes espaciais possibilita uma melhor compreensão do ordenamento espacial, fazendo com que o aluno conheça e domine o espaço geográfico". E essa compreensáo do espaço geográfico em que o aluno está inserido o ajudará a agir melhor sobre o mesmo e estabelecendo relaçóes mais conscientes no desenvolvimento de suas atividades.

Sem dúvida, quando o aluno participa do processo de construçáo do mapa, os signos e significados sáo compreendidos com mais facilidade. Conforme Duarte (2002), "a ideia associada ao estímulo físico forma o que se entende por "signo", que transmite a mensagem". Podemos perceber nesse conceito que o símbolo representa no mapa uma ideia, que chamamos de significado. Ainda segundo Duarte (op. cit.) "a "ideia" é o pensamento a ser transmitido pelo remetente, conhecida como significado".

Ao analisar as dificuldades de desenvolver novas metodologias no processo de ensino/aprendizagem, Steffanello (2009, p. 105) nos diz:

Mas, a questão é: como ensinar geografia com aulas interessantes e ao mesmo tempo esbarrando em dificuldades como a falta de recursos pedagógicos - globo, mapas, equipamentos audiovisuais, de informática, GPS - ou, ainda, "competindo" com o que as novas tecnologias apresentam aos nossos alunos fora da escola?

Dessa forma a metodologia proposta atende a demanda da nova sociedade tecnológica que utiliza cada vez mais recursos no seu cotidiano. E essa proposta metodológica de trabalhar com recursos tecnológicos têm a vantagem de tornar a aula mais interessante contribuindo com o melhor aprendizado para os alunos.

Continuando com o pensamento de Stefanello (2009): Nesse sentido, o ensino em sala de aula é um grande desafio e exige do professor, além de aulas expositivas dialogadas, uma didática diferenciada capaz de envolver os seus alunos, fazendo com que eles sejam participativos, críticos e que de fato produzam o saber geográfico escolar.

\section{METODOLOGIA}

\subsection{Local e sujeito:}

Os alunos do primeiro ano do Ensino Médio do Colégio Estadual Vila Maria, localizado no município de Barra
Mansa, estado do Rio de Janeiro, foram escolhidos para trabalharem com essa metodologia, pois os conteúdos abordados no projeto sáo integrantes da grade curricular desta série. No total foram 25 alunos que participaram da pesquisa.

\subsection{Desenvolvimento da atividade:}

No primeiro momento foram ministradas aulas de cartografia básica em sala, onde todos os conceitos básicos como, latitude, longitude, coordenada geográfica, carta, mapa, GPS, entre outros, foram abordados. Essas aulas têm como objetivo promover a alfabetização cartográfica nos alunos para que eles possam desenvolver o projeto e ao mesmo tempo não fiquem sem os conteúdos já definidos no programa escolar.

As primeiras aulas são teóricas e nada se distinguem de uma aula convencional do Ensino Médio, em que os conteúdos são abordados em sala. $\mathrm{O}$ único recurso didático diferente utilizado para facilitação da aprendizagem é o data show.

Após a parte teórica ser trabalhada em sala, o segundo passo foi ensinar aos alunos como manusear um aparelho de GPS. Como os conceitos básicos desse instrumento já haviam sido trabalhados em sala, não foi necessária uma nova aula teórica para o assunto. Os alunos foram levados pelo professor de Geografia para o pátio da escola onde foi realizada uma aula prática. Nessa atividade os alunos aprenderam a ligar o aparelho, utilizar as principais funçôes e fazer a leitura dos dados que o aparelho fornece.

Essa etapa foi muito simples, pois essa nova geraçáa está crescendo em um mundo cada vez mais tecnológico, onde vários tipos de aparelhos fazem parte do cotidiano deles, seja em suas casas ou nas ruas. Logo, manusear o GPS foi uma tarefa simples para os alunos, pois o mesmo se assemelha muito a um aparelho celular e todas as suas funçóes aparecem de forma simples na tela.

A primeira função importante do GPS ensinada para os alunos foi a de marcar waypoints. Isto é, fazer uma marca virtual em um determinado lugar do espaço geográfico. O aparelho de GPS registra a latitude, longitude, altitude, data e hora do local onde o waypoint foi marcado.

O processo de criaçáo dos waypoint possui uma vantagem para este trabalho, pois o aparelho possui vários símbolos para serem atribuídos aos pontos para facilitar a visualização e a diferenciação das referidas marcaçôes.

Esse recurso facilita aos alunos aprenderem os conceitos de signo e significado, que são essenciais ao estudo da cartografia para análise e interpretaçấo de mapas. Com os alunos participando da construçáo do mapa inserindo pontos de interesse, fica mais fácil trabalhar a interpretação dos mesmos, pois eles passam a compreender o que são os signos inseridos em cada mapa e o que eles representam. 
A próxima etapa do projeto foi sair com os alunos para a rua com a finalidade de registrar pontos utilizando o GPS e fotografar a área de cada registro. Para tanto, antes de sairmos para campo, fizemos um roteiro do caminho a ser percorrido e quais informaçóes seriam registradas. $\mathrm{O}$ itinerário escolhido foi a rua onde está situado o colégio, pois também é a principal rua do bairro. Seguimos até a altura do encontro com a única rua que corta a parte mais alta do bairro onde entramos em direção inversa ao que já havíamos caminhado. Seguimos até o final da referida rua chegando a uma transversal para voltarmos a rua principal em direção ao colégio.

Para realizar o projeto, foi montado um cronograma (Tabela 1) para organizar todas as etapas do processo, e como são duas aulas semanais na turma, cada encontro equivale a duas aulas.

\section{Tabela 1: Cronograma.}

\begin{tabular}{|l|l|}
\hline Aula & Atividade Realizada. \\
\hline 1 e 2 & Aula teórica sobre Conceitos Cartográficos. \\
\hline 3 e 4 & Aula teórica sobre Conceitos Cartográficos. \\
\hline 5 e 6 & Aula prática com GPS no pátio da escola para aprender as principais funçôes do aparelho. \\
\hline 7 e 8 & Reunião para definir itinerário a ser percorrido no campo e quais seriam os dados de coleta. \\
\hline 9 e 10 & Aula prática em campo: coleta dos dados e fotos \\
\hline 11 e 12 & Aula no laboratório de informática. Transferência dos dados para o computador. \\
\hline 13 e 14 & Aula no laboratório de informática. Confecção dos mapas utilizando o material coletado no campo. \\
\hline
\end{tabular}

\section{RESULTADOS E DISCUSSÃO}

Os dados coletados durante o trabalho serviram de base para desenvolvermos uma metodologia de construção de mapas que aproxima os conteúdos do currículo do $1^{\circ}$ ano do Ensino Médio a realidade dos alunos.

Nesta proposta foi possível transformar um problema real do bairro onde o colégio está localizado, que são as constantes enchentes provocadas por bueiros entupidos por conta de lixo e falta de manutenção, em um mapa de biorregiáo. Dessa forma conseguimos demonstrar, em outro tipo linguagem, a gráfica, uma situação/problema na qual os alunos enfrentam em seu cotidiano.

O lixo é jogado nos bueiros pelos moradores e nos períodos de chuvas no verão o bairro sofre com enchentes na sua área central e nas ruas longe do Rio Paraíba do Sul, por conta do grande número de bueiros entupidos ou com grande dificuldade de escoamento da água.

O itinerário percorrido pelo grupo por essas três ruas foi de aproximadamente 900 metros, e nesse percurso foram registrados 51 pontos (figura 1), sendo que cada ponto equivale a um bueiro.

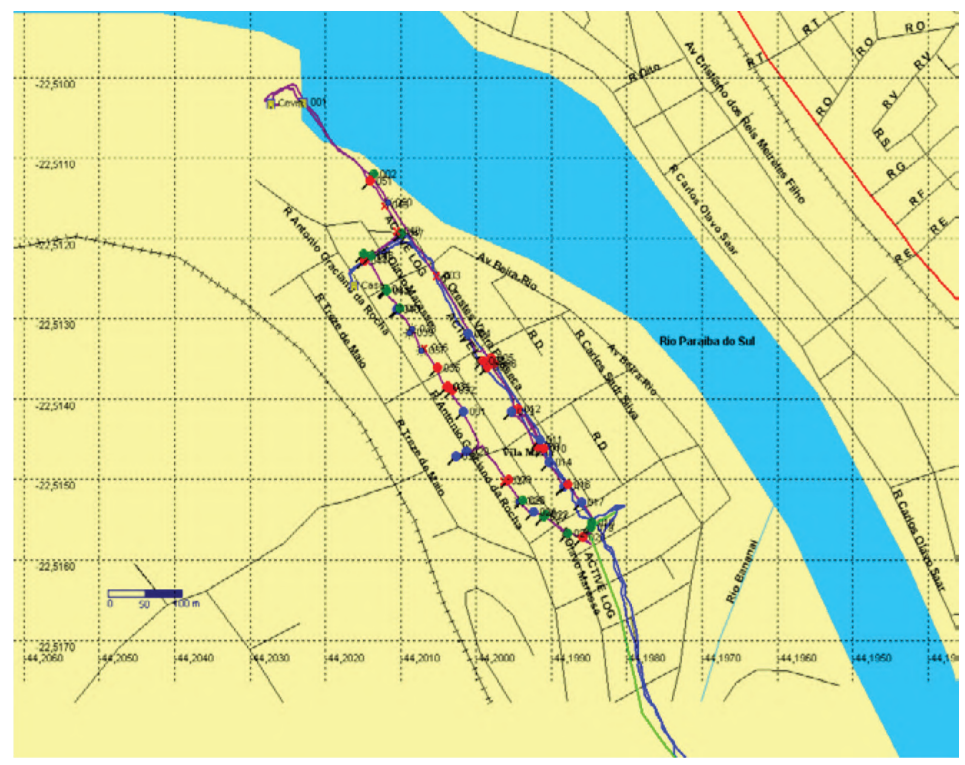

Figura 1: Caminho percorrido e waypoints. 
Foram tiradas 67 fotos ao longo do trecho percorrido, pois algumas cenas chamaram a atenção dos alunos, como entulho jogado nas ruas, lixo em bueiro (figura 2), bueiro fechado (figura 3) e água parada em terreno baldio.

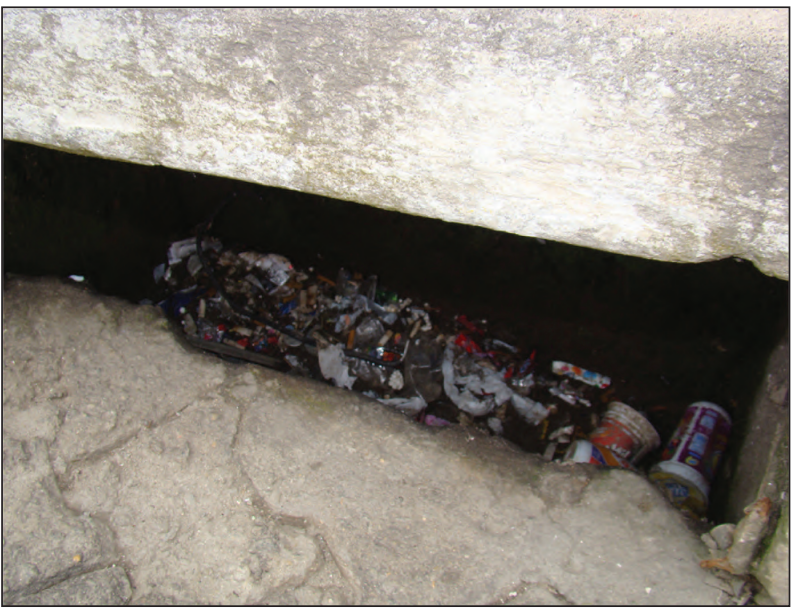

Figura 2: Lixo no bueiro.

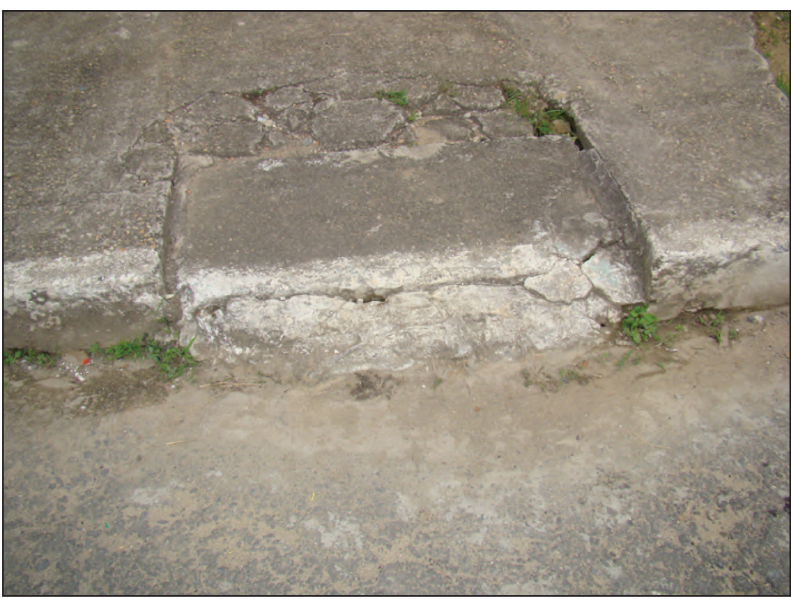

Figura 3: Bueiro fechado.

Esperamos que ao ficarem diante do problema, os alunos percebam os erros cometidos por parte da sociedade e que não repitam tais açóes em suas casas ou no seu cotidiano. E mais, que possam levar os conhecimentos aprendidos para as pessoas com quem eles convivem a fim de melhor o seu local de vivência transformando o espaço geográfico de forma positiva contribuindo para o bem estar de toda a população local.

Os alunos registraram cada ponto e cada foto em uma folha para posteriormente poderem consultar as informaçôes coletadas em campo e poderem utilizá-las quando estivessem processando a construção do mapa.

Os dados coletados pelos alunos foram levados para o laboratório de informática do colégio, onde foram transferidos para o computador. Utilizando o programa do próprio fabricante do GPS, que disponibiliza o software junto com o aparelho, os pontos registrados foram descarregados no programa, sendo possível ver pela primeira vez, antes mesmo de se trabalhar com os registros, a rota percorrida e os pontos marcados. Nesta etapa o resultado esperado é que os alunos visualizem no mapa o caminho que percorreram podendo distinguir os elementos naturais que observaram no percurso e os elementos culturais construídos pelos homens. Com esta atividade espera-se que os alunos desenvolvam o senso de localização e orientação, além de aperfeiçoarem a capacidade de leitura e interpretação dos diferentes tipos de mapas. Para tanto, esta etapa tem como objetivo desenvolver a percepção dos alunos que, visualizando o caminho percorrido com os pontos registrados inseridos no percurso, possam associar os signos e significados que os mapas apresentam.

No campo os alunos escolheram diferentes tipos de símbolos e cores para representar os diferentes tipos de ocorrências que encontraram. Com auxílio dos recursos do software, foi possível classificar cada informação. Com esse recurso é possível clicar sobre o ponto desejado e obter informaçóes sobre o local e o que ele representa (figura 4).

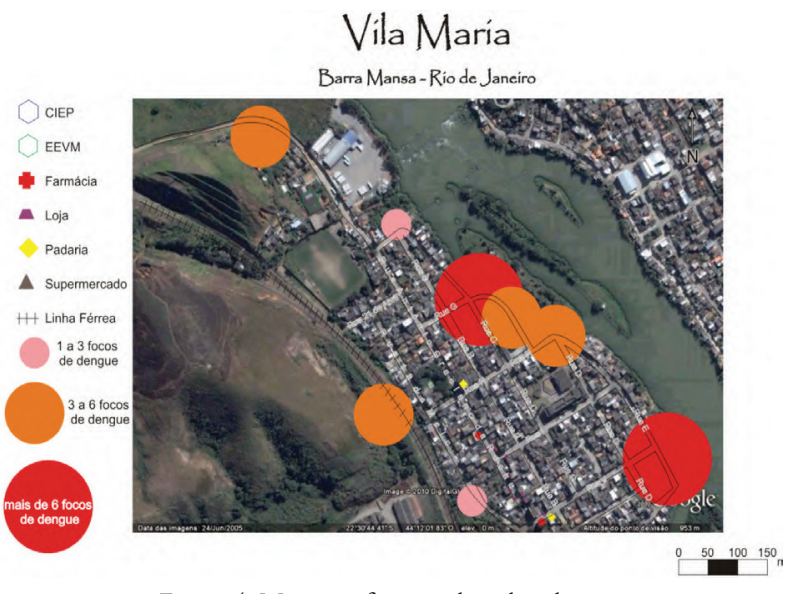

Figura 4: Mapa confeccionado pelos alunos.

Outro passo importante foi a criação de uma legenda para o mapa em criação. A legenda é um dos principais elementos de um mapa e, sendo assim, sua leitura é muito importante para o seu leitor. Construir uma legenda foi uma experiência muito positiva de aprendizagem, pois os alunos começaram a entender o que esse importante elemento do mapa quer passar para o leitor. Conceitos importantes, como Escala, Título, Latitude e Longitude também foram abordados no processo de construção do mapa, pois sem esses conceitos a leitura/interpretação ficam comprometidos.

$\mathrm{O}$ trabalho foi rendendo tantos frutos, que aproveitamos outro recurso do software para trabalhar com a ideia de Geoprocessamento e SIG (Sistema de Informação Geográfica). Loch (2006) define os SIG como uma ferramenta que oferece a possibilidade de integrar os dados de diferentes fontes e tipos, assim como a sua manipulação. Outro autor (Fitz, 2008) explica que o geoprocessamento, é entendido como uma técnica que, utilizando um SIG, busca a realização de levantamentos, análises e cruzamento de informaçóes georreferenciadas, visando à 
realização do planejamento, manejo e/ou gerenciamento de um espaço específico. Outra possibilidade que o programa Google Earth fornece foi a inserçáo das fotos em cada ponto percorrido. Os pontos que foram marcados em campo aparecem na imagem de satélite, também com cores e forma diferentes, e os alunos acrescentaram as fotos correspondentes a cada ponto. Com essa ferramenta, todos os leitores que forem utilizar esses dados, serão capazes de, além de observarem os diferentes problemas constatados em cada bueiro, poderão ver uma foto do local.

Para trabalhar com a ideia de geoprocessamento, foi pedido aos alunos que inserissem no mapa os principais pontos comerciais do bairro. Eles deveriam utilizar a mesma estratégia anterior de criar signos para cada marcação que considerassem importantes. Escolheram representar, a título de exercício, padaria, supermercado, farmácia e as lojas do bairro. Esta atividade é importante para o processo da alfabetização cartográfica, pois demonstra que os alunos conseguiram interpretar os signos e significados que os mapas apresentam, que existem diversos tipos de mapas e os mesmos podem ser alterados para representarem/localizarem diferentes tipos de informaçôes. Segundo Simielli (2007, p.98):

"o desenvolvimento destas noçóes contribui para a desmistificaçáo da cartografia como apresentadora de mapas prontos e acabados. O objetivo das representaçôes dos mapas e dos desenhos é transmitir informaçóes e não ser simplesmente objeto de reprodução".

\section{CONCLUSỐES}

O trabalho realizado pelos alunos e os comentários que surgiram sobre o mesmo nos permitiu indicar que o objetivo da atividade foi atingido, pois os alunos conseguiram construir mapas utilizando o GPS, e consequentemente, facilitando o processo de ensino/aprendizagem quando da análise dos signos/significados que os mapas possuem.

A metodologia agradou tanto aos professores quanto os alunos, pois os alunos se sentiram motivados com essa abordagem tecnológica e prática de relacionar conteúdos. Também os professores que acompanharam o desenvolvimento e a participação dos alunos nas atividades propostas gostaram do resultado final do projeto. As limitaçóes do trabalho ficaram por conta das dificuldades de recursos disponíveis na escola. Só havia uma máquina fotográfica e 8 computadores para uma turma de 25 alunos. Como a escola náo possui um aparelho GPS, o professor de Geografia emprestou o instrumento para realizaçáo da pesquisa. Outro importante fator é o pouco tempo disponível para a realização da atividade, pois como são apenas duas aulas por semana na turma, não podemos deixar de avaliar os alunos, cumprir o conteúdo e não sobra muito tempo para realizar projetos dessa natureza.

\section{REFERÊNCIAS}

1. BERG, Peter. Como mapear a sua própria biorregião. In: STONE, Michael K.; BARLOW, Zenobia (Orgs.). Alfabetização Ecológica: a educação das crianças para um mundo sustentável. São Paulo: Cultrix, 2006.

2. BRASIL. Política Nacional de Educaçáo Ambiental. Lei no 9.795. 1999 (Disponível em: http://www.planalto. gov.br/ccivil_03/Leis/L9795.htm. Acesso em 27/02/11).

3. CARVALHO, Isabel Cristina de Moura. Educaçáo ambiental: a formaçáo do sujeito ecológico. 5. ed. São Paulo: Cortez, 2011.

4. DUARTE, Paulo Araújo. Fundamentos de Cartografia. Florianópolis: Editora da UFSC, 2002.

5. FITZ, Paulo Roberto. Cartografia Básica. São Paulo: Oficina de Textos, 2008.

6. LOCH, Ruth E. Nogueira. Cartografia: representação, comunicaçáo e visualizaçáo de dados espaciais. Florianópolis: Editora da UFSC, 2006.

7. PONTUSCHKA, Nídia Nacib. A geografia: pesquisa e ensino. In CARLOS, Ana Fani Alessandri (org). Novos Caminhos da Geografia. São Paulo: Contexto, 2001.

8. REIGOTA, Marcos. O que é educaçáo ambiental. 2. ed. São Paulo: Brasiliense, 2009.

9. RODRIGUES, Angélica Cosenza. A Educação Ambiental e o fazer interdisciplinar na escola. Juiz de Fora: Junqueira \& Marin, 2008.

10. STEFANELLO, Ana Clarissa. Didática e avaliaçáo da aprendizagem no ensino de geografia. São Paulo: Saraiva, 2009.

11. TEIXEIRA, Elizabeth. As três metodologias: acadêmica, da ciência e da pesquisa. 6. ed. Petrópolis: Vozes, 2009.

Endereço para Correspondência:

Daniel de Sampaio - professordanieldesampaio@yahoo.com.br Rua Prefeito Joấo Luiz, 957

Saudade - Barra Mansa - RJ

CEP: 27350-350 